University of Nebraska - Lincoln

DigitalCommons@University of Nebraska - Lincoln

Publications, Agencies and Staff of the U.S.

Department of Commerce

U.S. Department of Commerce

2011

What's the catch? Patterns of cetacean bycatch and depredation in Hawaii-based pelagic longline fisheries

Karin A. Forney

NOAA, karin.forney@noaa.gov

Donald R. Kobayashi

NOAA

David W. Johnston

Duke University Marine Laboratory, david.johnston@duke.edu

Jamie A. Marchetti

NOAA

Michael G. Marsik

NOAA

Follow this and additional works at: https://digitalcommons.unl.edu/usdeptcommercepub

Part of the Environmental Sciences Commons

Forney, Karin A.; Kobayashi, Donald R.; Johnston, David W.; Marchetti, Jamie A.; and Marsik, Michael G., "What's the catch? Patterns of cetacean bycatch and depredation in Hawaii-based pelagic longline fisheries" (2011). Publications, Agencies and Staff of the U.S. Department of Commerce. 263.

https://digitalcommons.unl.edu/usdeptcommercepub/263

This Article is brought to you for free and open access by the U.S. Department of Commerce at DigitalCommons@University of Nebraska - Lincoln. It has been accepted for inclusion in Publications, Agencies and Staff of the U.S. Department of Commerce by an authorized administrator of DigitalCommons@University of Nebraska - Lincoln. 
SPECIAL TOPIC

\title{
What's the catch? Patterns of cetacean bycatch and depredation in Hawaii-based pelagic longline fisheries
}

\author{
Karin A. Forney ${ }^{1}$, Donald R. Kobayashi ${ }^{2}$, David W. Johnston ${ }^{3}$, Jamie A. Marchetti ${ }^{4}$ \& Michael \\ G. Marsik ${ }^{4}$ \\ 1 Southwest Fisheries Science Center, National Marine Fisheries Service, NOAA, Santa Cruz, CA, USA \\ 2 Pacific Islands Fisheries Science Center, National Marine Fisheries Service, NOAA, Honolulu, HI, USA \\ 3 Division of Marine Science and Conservation Nicholas School of the Environment, Duke University Marine Laboratory, Beaufort, NC, USA \\ 4 Pacific Islands Regional Office, National Marine Fisheries Service, NOAA, Honolulu, HI, USA
}

\section{Keywords}

Bycatch; cetacean; depredation; false killer whale; generalized additive models; pelagic longline.

\section{Correspondence}

Karin A. Forney, Southwest Fisheries Science Center, National Marine Fisheries Service, NOAA, 110 Shaffer Road, Santa Cruz, CA, USA.

E-mail: karin.forney@noaa.gov

Accepted: 8 April 2011

doi:10.1111/j.1439-0485.2011.00454.x

\begin{abstract}
U.S. Pacific pelagic longline fisheries operating in the central North Pacific have been subject to a series of regulations to reduce bycatch of protected species, including seabirds and sea turtles. Cetaceans are also occasionally caught, and the bycatch of false killer whales, Pseudorca crassidens, in the Hawaii-based deep-set longline fishery currently exceeds allowable levels under the Marine Mammal Protection Act (MMPA). In this study, we examined longline observer data collected between 1994 and 2009, with emphasis on 2003-2009, to identify patterns of cetacean bycatch and depredation in relation to area, time, vessel, habitat variables, fishing gear, and set characteristics. The objectives of these analyses were to identify relationships amongst fishery interaction rates and variables that could provide opportunities to reduce depredation by cetaceans, reduce the likelihood of incidentally catching a cetacean when present, or reduce the severity of injuries to cetaceans if caught. The results of this study were provided to the False Killer Whale Take Reduction Team, convened under the MMPA, as they developed a plan to reduce serious injury and mortality of false killer whales in these fisheries. No correlates were identified that could markedly reduce depredation rates, but a slight (16\%) reduction in repeat depredation within a fishing trip was evident when vessels moved at least $100 \mathrm{~km}$ following a depredation event. The most practical option for reducing bycatch of false killer whales was determined to be the use of small $(14 / 0-16 / 0)$ circle hooks, which could result in an estimated 6\% reduction in bycatch and a greater likelihood of releasing animals with non-serious injuries. Additional research is needed to address unresolved questions relating to processes involved in depredation events and hookings or entanglements of false killer whales.
\end{abstract}

\section{Introduction}

Anthropogenic activities in the world's oceans are increasingly recognized as a threat to marine biodiversity and the health of marine ecosystems (Norse 1995; Gray 1997; Agardy 2000; Derraik 2002; Cheung et al. 2009). Incidental catch of non-target species (bycatch) in fisheries is recognized as a factor affecting populations of fish, seabirds, sea turtles, and marine mammals worldwide (Hall et al. 2000; Lewison et al. 2004; Read et al. 2006). During the last decade, U.S. pelagic longline fisheries that operate out of Hawaii (targeting bigeye tuna, Thunnus obesus, and swordfish, Xiphias gladius) have been subject to regulations to reduce bycatch of several species, including sea 
turtles, seabirds, and sharks (Gilman et al. 2007, 2008). These fisheries also occasionally injure or kill dolphins or whales that become hooked or entangled (Forney \& Kobayashi 2007), in some cases when animals are actively depredating catch or bait. False killer whales, Pseudorca crassidens, are known to depredate catch in pelagic longline fisheries (Donoghue et al. 2002; TEC 2009), causing economic losses and increasing the likelihood that they will become hooked or entangled in longline gear. Under the U.S. Marine Mammal Protection Act (MMPA), marine mammal populations are assessed every 1-3 years to determine whether anthropogenic activities are adversely affecting each stock (e.g. Carretta et al. 2010), and these assessments have repeatedly determined that the bycatch of false killer whales in Hawaii-based fisheries exceeds allowable levels. As a result, the National Marine Fisheries Service (NMFS) convened a Take Reduction Team (TRT) in January 2010 (75 FR 2853, 19 January 2010) to develop a draft plan to reduce the incidental mortality and serious injury of false killer whales. The MMPA specifically requires that serious injuries to marine mammals (Andersen et al. 2008) are considered along with deaths when evaluating impacts, and take reduction efforts must reduce the level of combined deaths and serious injuries.

In support of the False Killer Whale Take Reduction Team process, this study examines patterns of false killer whale depredation and bycatch in Hawaii-based longline fisheries, to identify potential correlates that might aid in reducing bycatch of false killer whales and other cetaceans. The analysis is based on a four-tiered approach towards reducing impacts to false killer whales: (i) reduce the spatiotemporal overlap between fisheries and false killer whales; (ii) reduce the likelihood of depredation when fishing operations take place in areas with false killer whales; (iii) reduce the likelihood that a false killer whale will become hooked or entangled when it is in contact with catch, bait, or gear; and (iv) reduce the severity of injuries sustained by the false killer whale when it is hooked or entangled. Each of these processes, alone or in combination, can potentially contribute towards bycatch reduction goals if correlates of depredation or bycatch are identified. In this study, we have conducted analyses of detailed longline observer data collected in Hawaii-based longline fisheries between 1994 and 2009, with emphasis on 2003-2009, to identify potential correlates and mitigation measures.

\section{Material and Methods}

Fishery observer data

Two discrete pelagic longline fisheries are based in Hawaii: a deep-set fishery targeting tunas and a shallow- set fishery targeting swordfish (WPFMC 2010). The NMFS Pacific Islands Region Observer Program has monitored Hawaii-based pelagic longline fisheries since 1994, initially with low levels of coverage (4\%) and subsequently increasing to at least $20 \%$ of the deep-set fishery since 2001 and $100 \%$ of the shallow-set fishery since 2004. The program systematically documents effort, gear and set characteristics, catch of target and non-target species, and protected species bycatch. False killer whale bycatch has primarily been documented in the deep-set fishery ( $\mathrm{n}=39$ on trips initiated during 1994-2009), although four false killer whales were reported hooked or entangled in shallow sets (Forney \& Kobayashi 2007; Forney 2010). Details of all cetacean hookings or entanglements are reviewed by NMFS staff following the trip to determine the severity of injuries sustained in the interaction (e.g. Forney 2010), using established guidelines (Andersen et al. 2008).

Since about August 2003, observers have also systematically recorded depredation (damage to catch), and they have been trained to identify and record whether depredation was caused by cetaceans, sharks, squid, seabirds, or other species. The quantitative analyses of depredation and bycatch rates presented below are based on Hawaii longline observer program data for August 2003 through December 2009, excluding some vessels that participated in 2003-2006 gear research during and subsequent to the experiments. These vessels had the option of retaining the experimental gear and thus are not representative of the remainder of the fishery. The resulting subset of the data (summarized in Table 1) covers 20,724 deep sets made on 1632 trips completed during 2003-2009 and 6228 shallow sets made on 356 trips completed during 2004 2009 (the shallow-set fishery was closed during 2003). A total of 29 serious injuries or deaths of false killer whales remained in this data subset (Table 1). An additional six animals that were injured could only be identified as 'blackfish' (in this case, false killer whales or short-finned pilot whales, Globicephala macrorhynchus) and were included in some of the analyses to increase sample sizes.

\section{Habitat data}

Satellite-derived environmental data were extracted for each haul-begin location and date. Data sets were of two types: dynamic (varying over space and time) or static (fixed over space or time). Dynamic variables include sea surface temperature (SST; Pathfinder weekly gridded at $0.1^{\circ}$ ), ocean color (SeaWiFS monthly chlorophyll gridded at $0.1^{\circ}$ ), sea surface height ( $\mathrm{SSH}$, AVISO weekly gridded at $0.25^{\circ}$ ), and $\mathrm{SSH}$-derived variables (geostrophic current components). Static variables include sea-floor bathymetry and bathymetry-derived variables. These were 
Table 1. Summary of the 2003-2009 observer dataset used for the modeling and simulation analyses. Sets with depredation are those for which observers recorded at least one catch item damaged by marine mammals. Sets without depredation are those for which no damage by marine mammals was recorded, but depredation may not always be observable.

\begin{tabular}{|c|c|c|c|c|c|c|}
\hline & \multicolumn{2}{|l|}{ Total } & \multicolumn{2}{|c|}{$\begin{array}{l}\text { With bycatch of false killer } \\
\text { whales }\end{array}$} & \multicolumn{2}{|c|}{$\begin{array}{l}\text { With bycatch of false killer } \\
\text { whales or blackfish }\end{array}$} \\
\hline & No. sets & $\%$ sets & No. sets & $\%$ sets & No. sets & $\%$ sets \\
\hline \multicolumn{7}{|l|}{ Deep-set } \\
\hline With depredation & 1179 & 6 & 19 & 1.61 & 22 & 1.87 \\
\hline Without depredation & 19545 & 94 & 9 & 0.05 & 11 & 0.06 \\
\hline Total & 20724 & & 28 & 0.14 & 33 & 0.16 \\
\hline \multicolumn{7}{|l|}{ Shallow-set } \\
\hline With depredation & 183 & 3 & 0 & 0.00 & 0 & 0.00 \\
\hline Without depredation & 6045 & 97 & 1 & 0.02 & 2 & 0.03 \\
\hline Total & 6228 & & 1 & 0.02 & 2 & 0.03 \\
\hline
\end{tabular}

estimated for each haul-begin location from satellitederived bathymetry (Smith \& Sandwell 1997). This dataset is gridded at $0.033^{\circ}$ resolution and includes depth as well as two directional gradients (east/west, north/south) and a distance calculation to the nearest 200-fathom (366-m) contour. These environmental data were extracted from weekly (SST, AVISO), monthly (SeaWiFS) or fixed (bathymetric) data grids by spatial interpolation of corresponding haul-begin locations using the GMT subroutine of grdtrack (Wessel \& Smith 1991). It should be noted that the set information based on the haul-begin location is only an approximate representation of the true distribution of hooks because the longlines are tens of miles long.

The haul-begin locations were also merged with a new oceanographic data product that quantifies individual geostrophic eddies from a time-series of remotely sensed altimetry fields (Chelton et al. 2007, 2011). These energetic mesoscale features have scales of tens to hundreds of kilometers and tens to hundreds of days and account for most of the variability in the ocean, being one of the primary dynamic features along with large oceanic currents and gyres (Klein \& Lapeyre 2009). The eddy dataset was created with a procedure that automatically processes SSH data from satellite altimeters and tracks eddy trajectories over time and space, using the AVISO dataset. Eddies were identified with this procedure from closed SSH contours, as described in detail by Chelton et al. (2011). In addition to their identification in time and space, eddies can be characterized by attributes such as effective radius, amplitude, edge SSH, and geostrophic rotational speed. Eddy shapes were approximated as circles using the effective radius, and the haul-begin locations were compared with points along the circle perimeter and the central location of each eddy to calculate minimum distances. Eddies were classified as either cyclonic or anticyclonic by the nature of their SSH anomaly (negative SSH anomaly = cyclonic; positive SSH anomaly = anticyclonic) and further classified by eddy strength, as indicated by the ratio of vertical amplitude and the effective eddy radius, which is highly correlated with the maximum rotational geostrophic speed within the eddy. Amplitude values in the dataset were defined as the absolute difference between the SSH contour along the edge of the eddy and the most extreme value within the eddy interior. For the purposes of this study, ratios $>0.065$ (median eddy strength over the domain of study) were classified as strong eddies. Using this merging of datasets, 12 minimum-distance measures were calculated for each set's haul-begin location, reflecting a nested ordering based on eddy type (cyclonic or anticyclonic), strength (any strength or strong), and the feature of interest (eddy edge or center), respectively.

\section{Analytical methods}

All analyses focused on false killer whales, but blackfish were included in some tests to increase sample sizes. The deep-set and shallow-set fisheries were considered separately in the analyses because there are considerable differences in the geographic distribution of effort, seasonal timing, day/night setting, species targeted, and gear and set characteristics. Furthermore, the majority of analyses were restricted to the deep-set fishery, where most false killer whales have been caught. Hook types used in the two fisheries were categorized as follows, based on the reported majority hook type used on a trip: large circle hooks (18/0, required in the shallow-set fishery), small circle hooks (14/0-16/0 sizes), tuna hooks (3.4-3.8 mm wire diameter), and 'other hooks', which included mostly $8 / 0$ or $9 / 0$ J-hooks. 
Three steps were included in the present analysis. First, a series of descriptive plots and summaries were created to examine spatial and seasonal trends in depredation and bycatch for each fishery (based on the 2003-2009 data subset) and to investigate within-set patterns of bycatch (based on all false killer whale interactions in the 1994-2009 observer data). Spatial data were aggregated into $2 \times 2^{\circ}$ squares for plotting to preserve confidentiality as required under the Magnuson-Stevens Fishery Conservation and Management Reauthorization Act of 2006. Secondly, generalized additive models (GAM, Hastie \& Tibshirani 1990) were developed to evaluate potential covariates only in the deep-set longline fishery, because most bycatch and depredation took place in this fishery. Binomial GAMs were constructed in S-PLUS to describe the presence or absence of depredation and bycatch as a function of various predictors (Table 2), allowing up to three degrees of freedom and using cubic smoothing splines. Thirdly, following these exploratory analyses, bootstrap simulations were performed to evaluate potential effects of changes in gear, areas fished, or other fishing characteristics on expected rates of depredation and false killer whale or blackfish bycatch. These simulations randomly drew sets, with replacement, from all sets in the database that met pre-specified input criteria (e.g. fishing restricted only to certain gear types). Based on 1000 replicates, the means and distributions of expected bycatch and depredation were examined to evaluate whether reductions could be achieved.

Table 2. Variables included as potential predictors in the GAMs.

\begin{tabular}{ll}
\hline Set and gear variables & Environmental variables \\
\hline Latitude (LAT) & Sea surface temperature (SST) \\
Longitude (LON) & SST gradient (SSTGRAD) \\
Year (YR) & Sea surface height (SSH) \\
Month (MON) & SeaWiFS Chlorophyll (CHL) \\
Vessel (VSL) & Water depth (BATHY) \\
Hook type (HK.TYPE) & North/south bathymetric slope \\
& (BATHY.DU) \\
No. hooks set (HKS.SET) & East/west bathymetric slope \\
& (BATHY.DV) \\
No. floats (NUM.FLTS) & Zonal geostrophic currents \\
& (GEO.U) \\
Soak time (SOAK.TIME) & Meridional geostrophic currents \\
& (GEO.V) \\
Mainline length & Distance to 200-fm (366 m) \\
(MNLN.LEN) $_{\text {Haul begin hour (HOUR) }}^{\text {isobath }}$ \\
Bait type, squid or fish (BAIT) \\
No. fish caught (CATCH.ALL) & 12 distance to eddy measures for \\
No. bigeye tuna & Cyclonic versus anticyclonic \\
caught (CATCH.TGT) & Strong versus any strength \\
\hline
\end{tabular}

${ }^{\mathrm{a} C}$ Categorical variables.
The analyses and simulations focused on the following three questions:

1 Do rates of catch depredation by cetaceans in the longline fishery vary with respect to geographic area, habitat, target species, vessel, gear, or set characteristics? This question was addressed using the 20032009 data subset, for which depredation information was systematically collected.

2 When cetaceans are known to have been in contact with catch or gear, do bycatch rates of false killer whales and blackfish vary with respect to geographic area, habitat, vessel, gear, or set characteristics? To increase statistical power, this question was addressed using only the subset of the 2003-2009 data during which cetaceans were known to have come in contact with catch or gear. (The vast majority of sets had no evidence of cetacean presence, and including these sets would have resulted in a very large number of zeros and a low signal-to-noise ratio for examining bycatch rate patterns).

3 When false killer whales or blackfish are hooked or entangled, does the outcome (death, serious injury, or non-serious injury of the animal, Andersen et al. 2008) vary with set or gear characteristics? This question was examined using all documented hookings or entanglements in the complete 1994-2009 dataset to maximize sample sizes for comparison.

\section{Results}

\section{Cetacean species caught}

Since 1994, a diverse suite of cetacean species have been incidentally caught in Hawaii-based pelagic longline fisheries (Forney \& Kobayashi 2007; Forney 2010), including false killer whale, short-finned pilot whale, Risso's dolphin (Grampus griseus), common bottlenose dolphin (Tursiops truncatus), striped dolphin (Stenella coeruleoalba), pantropical spotted dolphin (Stenella attenuata), spinner dolphin (Stenella longirostris), short-beaked common dolphin (Delphinus delphis), Blainville's beaked whale (Mesoplodon densirostris), sperm whale (Physeter macrocephalus), humpback whale (Megaptera novaeangliae), and Bryde's whale (Balaenoptera edeni). Three species (short-finned pilot whale, false killer whale, and bottlenose dolphin) have been observed depredating catch or bait, although false killer whales have most frequently been implicated. Species composition of the cetacean bycatch varied between deep-set and shallow-set fisheries and matched patterns of cetacean species distributions, with tropical species caught more commonly in the more southerly deep-set fishery (Fig. 1) and temperate species more commonly in the more northerly shallow-set fishery. Bycatch levels 

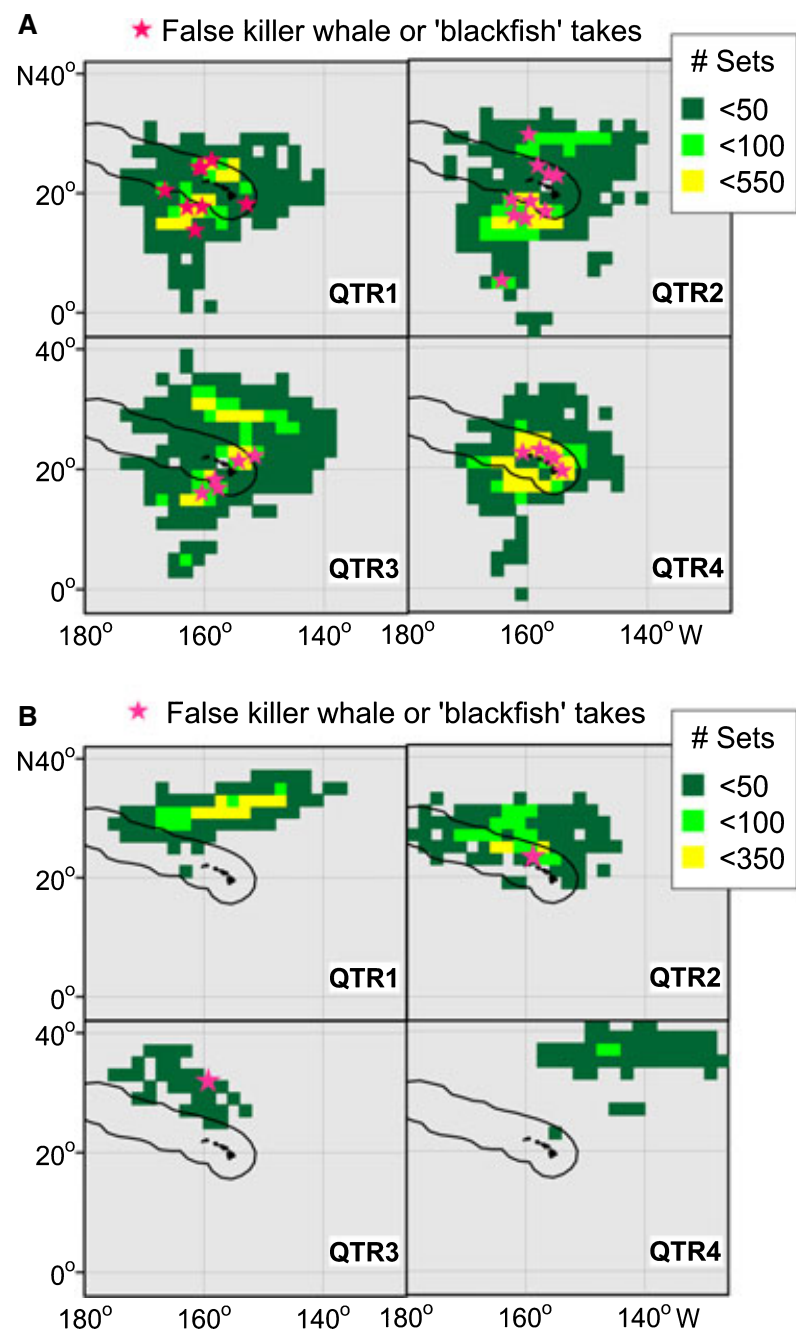

Fig. 1. Distribution of quarterly (QTR) fishing effort in the 2003-2009 observer data, by $2 \times 2^{\circ}$ latitudinal square, and locations of false killer whale or 'blackfish' hookings/entanglement (stars) in (A) the deep-set and $(B)$ the shallow-set longline fishery.

during the study period were at or below allowable levels specified under the MMPA for all species except false killer whales.

\section{Spatial and temporal patterns}

The deep- and shallow-set longline fisheries seasonally operate in different geographic areas, and patterns of false killer whale bycatch largely mirrored the effort distribution (Fig. 1). In the shallow-set fishery, one false killer whale and one blackfish were recorded caught in the 2003-2009 dataset, and depredation of catch by marine mammals was documented in 183 out of 6228 sets $(3 \%$, Table 1). In the deep-set fishery, 28 false killer whales and five blackfish were caught, and depredation was documented in 1179 of 20,724 sets (6\%). Most deep-set fishing effort took place within about $400 \mathrm{~km}$ of the Hawaiian Islands, and this is also where most false killer whales and blackfish were observed hooked or entangled. Taking fishing effort into account (Fig. 2), rates of depredation in the deep-set fishery did not exhibit any clear pattern with respect to geographic location or target species (bigeye tuna) catch rates.

\section{Within-set patterns of depredation and bycatch}

An examination of all 43 hookings or entanglements of false killer whales between 1994 and 2009 revealed a tendency for animals to be caught on hooks located at the mid-point between floats (Fig. 3). In many cases, false killer whales were hooked or entangled following a succession of hooked fish exhibiting marine mammal damage, suggesting the whales moved along the line depredating catch until they became caught themselves. A wide variety of fish species were targeted by the whales: in the sets with evidence of depredation, damage rates were greatest for billfishes (20\% of caught individuals), wahoo (Acanthocybium solandri, 19\%), tunas (Thunnus spp., 18\%), moonfish (Lampris spp., 12\%), and mahimahi (Coryphaena spp., 9\%) (see Oleson et al. 2010 for additional details). Sharks were rarely depredated, as only one of 6669 sharks caught in sets with evidence of catch depredation was reported to have marine mammal damage.

The 43 false killer whale interactions included hookings $(n=36)$, entanglements $(n=4)$, both $(n=2)$, or unknown method of capture $(n=1)$. Interaction outcomes included three deaths, 33 serious injuries, and five non-serious injuries (Forney 2010; see Andersen et al. 2008 for serious injury determination criteria). Serious injuries were most commonly caused by hooks that were in the mouth or ingested. Two of the three deaths involved entanglements, and non-serious injuries mostly resulted when the animals pulled free of the hook or when all line was removed prior to release (Forney 2010). Although the majority (73\%) of deep-set trips observed between 1994 and 2009 used primarily tuna hooks, some comparison of the potential effect of hook type was possible. In the deep-set fishery, the hook type was known for 40 caught false killer whales or blackfish: 36 animals (90\%) were caught on tuna hooks and four were caught on small circle hooks. The binomial probability of having at least 36/40 animals caught on tuna hooks, given the observed proportion of trips using mostly tuna hooks is only $0.5 \%$, suggesting that tuna hooks are more likely to capture false killer whales or blackfish than other hook types (mostly small circle hooks). This pattern was further evaluated in the simulations described below. 
Fig. 2. Spatial summary of the 2003-2009 deep-set longline fishery observer data: observed effort (number of hooks set), bigeye tuna catch rates per 1000 hooks, false killer whale and blackfish (PC\&BF) take rates per million hooks set, and three measures of depredation rates (MM damaged fish) for the 2003-2009 observer data included in the present analyses.
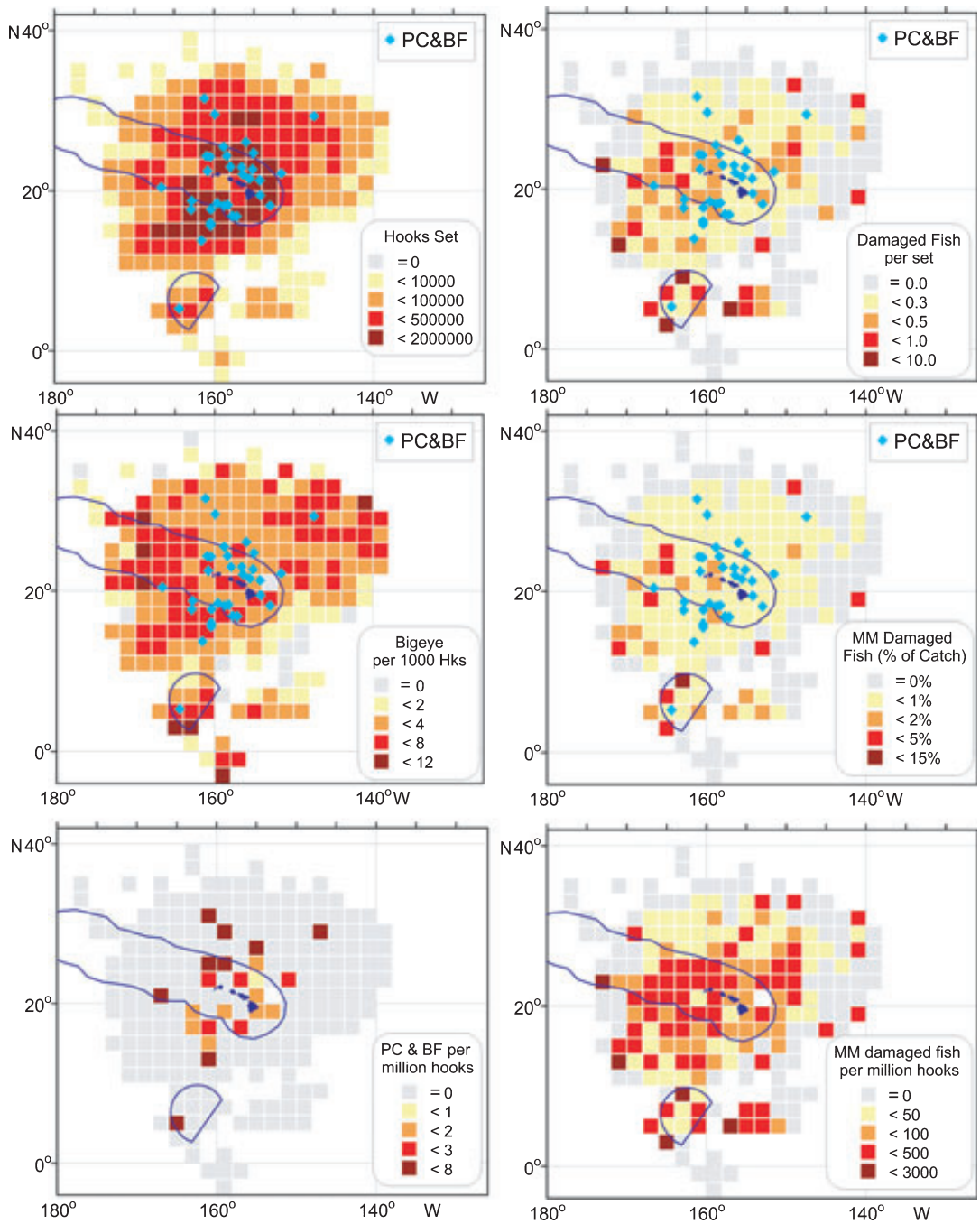

The proportions of animals seriously injured or killed versus not seriously injured varied between the two most common hook types, tuna hooks and small circle hooks. Only 6\% (two of 36) of the tuna-hooked blackfish were released with non-serious injuries, whereas 25\% (one of four) of the small-circle-hooked blackfish were released with non-serious injuries, as the hook pulled out or the animal was able to disentangle itself when the hook let go of the entangling line. However, this sample size is still quite small and these rates are not statistically different from the combined average rate of non-serious injury $(3 / 40=8 \% ; \mathrm{P}=0.25)$, based on binomial probabilities. If five short-finned pilot whale interactions with known hook types are included in the above comparison to increase sample sizes, the proportion of non-serious injuries on small circle hooks increases to $50 \%$ (three of six), which has only a $2 \%$ binomial probability of occurrence based on the average for all hook types $(5 / 45=11 \%$ not seriously injured). Thus, small circle hooks may cause fewer deaths or serious injuries in false killer whales and short-finned pilot whales, but increased sample sizes are required to evaluate fully whether the use of small circle hooks can result in lower rates of death and serious injury for false killer whales fleet wide.

\section{GAMs of depredation rates}

A GAM predicting presence or absence of depredation was used to examine effects of individual variables while controlling for other potential confounding factors. The 'best fit' generalized additive model (selected based on Akaike's information criterion, AIC) predicting depredation rates in the deep-set longline fishery included 10 variables: latitude, longitude, year, month, number of hooks set, soak time, total catch, water depth (BATHY), east-west bathymetric slope (BATHY.DV), and vessel (Table 3, Fig. 4), but overall explained deviance for this model was quite low $(6.6 \%)$. Potential causes of the 


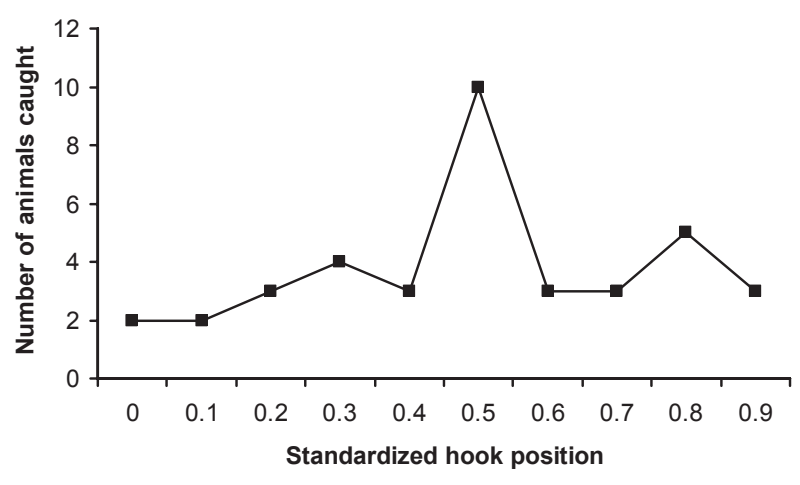

Fig. 3. Standardized hook position within each basket, or section of mainline between successive floats, for 43 false killer whales hooked or entangled in longline sets during 1994-2009. Dataset includes one animal taken during a 2009 trip that returned to port in early 2010 . There were four to five hooks per basket in four shallow sets that caught one false killer whale each, and 22-30 hooks per basket for 38 deep sets that caught 39 false killer whales.

apparent individual vessel effects were examined in more detail, including hook types used, areas fished, vessel size, and set and gear characteristics, but no commonalities were identified that might explain the apparent higher depredation rates for these vessels. The extent to which false killer whales might follow individual fishing vessels to depredate consecutive sets has not been systematically documented, but the observer data allowed an empirical evaluation of the frequency of depredation relative to prior depredation events. Within trips, sets that were preceded by sets without depredation had a significantly

Table 3. Results for the best-fit GAM predicting depredation rate in the deep-set fishery. Vessel effects were included as a categorical variable (VSL).

\begin{tabular}{lrrrr}
\hline Variable & $d f$ & Npar df & \multicolumn{1}{c}{$\chi^{2}$} & \multicolumn{1}{l}{$P$} \\
\hline (Intercept) & 1 & & & \\
s(LAT) & 1 & 2.8 & 21.238 & $<0.0001$ \\
s(LON) & 1 & 3 & 9.702 & 0.0212 \\
s(YR) & 1 & 2.9 & 11.065 & 0.0099 \\
s(MON) & 1 & 2.8 & 22.511 & $<0.0001$ \\
s(HKS.SET) & 1 & 3 & 7.939 & 0.0476 \\
s(SOAK.TIME) & 1 & 3 & 13.236 & 0.0042 \\
VSL & 143 & & & \\
s(CATCH.ALL) & 1 & 2.8 & 63.780 & $<0.0001$ \\
s(BATHY) & 1 & 2.8 & 7.209 & 0.0567 \\
s(BATHY.DV) & 1 & 2.8 & 12.347 & 0.0052 \\
Null deviance: 9043.15 on 20,720 degrees of freedom & \\
Residual deviance: 8443.19 on 20,542 degrees of freedom & \\
\hline
\end{tabular}

$\mathrm{df}=$ degrees of freedom; Npar = non-parametric. See Table 2 for variable abbreviations.

[Corrections added after online publication 8 June 2011 - '7.9391'

changed to '7.939'; the final 's(BATHY)' changed to 's(BATHY.DV)'. lower depredation rate of 5\% (941/18,010 sets) compared to $14 \%(148 / 1082)$ when the preceding set had depredation (chi-squared test, $\mathrm{P} \leq 0.0001$ ). A GAM was used to investigate whether there was a minimum or optimal distance between sets that would reduce the likelihood of repeat depredation. The pattern was non-linear and suggested that a $16 \%$ reduction in repeat depredation rate (from 14 to $12 \%$ ) could be achieved by moving $100 \mathrm{~km}$ after experiencing depredation; greater distances did not further reduce the likelihood of repeat depredation. The time interval between sets might also influence depredation rates, but the available observer data did not include sufficient variation in the time between consecutive sets within a trip to evaluate potential temporal effects.

\section{GAMs of bycatch rates}

As for depredation above, binomial GAMs were developed to predict the presence of false killer whale or blackfish bycatch. Only those sets during which cetaceans were known to have interacted with catch or gear were included in the model to reduce the large number of zeros in the full dataset and increase statistical power. The best fit model included year, number of floats, total catch, sea surface temperature, and sea surface height, with $18 \%$ of variation explained (Table 4, Fig. 5). This contrasts with the results of a Poisson GAM for all 20032009 sets, aggregated by $2 \times 2^{\circ}$ geographic block, which indicated that effort alone (the total number of hooks set) explained $43 \%$ of the variation in the number of bycaught false killer whales or blackfish. Thus, bycatch is most closely linked to overall fishing effort, and setspecific factors have limited additional explanatory power.

\section{Simulation results}

Based on the patterns identified above, bootstrap simulations were performed to evaluate potential fleet-wide reductions in bycatch if specific effort restrictions and/or gear modifications were implemented. The simulations considered small-scale area closures, shifts in effort from the deep-set to shallow-set fishery, and potential gear modifications (e.g. required use of small circle hooks in the deep-set fishery). There was also an input parameter to specify the proportion of interactions that would result in non-serious injury rather than death or serious injury, to simulate potential reductions in injury severity that might be achieved through the use of small circle hooks, weaker hooks that could more easily straighten if a cetacean were caught, and/or increased efforts by captain and crew to free animals from all gear. This latter point was considered especially important by the TRT, because crew on longline vessels 
Fig. 4. Functional forms and standard error bands for the predictors of depredation included in the best-fit GAM. In the bottom panel, each vertical bar represents a separate vessel, and vessels with higher depredation rates are shown with thicker symbols and error bars. In the upper panels, $s(x)$ represents the smoothing spline of the indicated predictor variable.
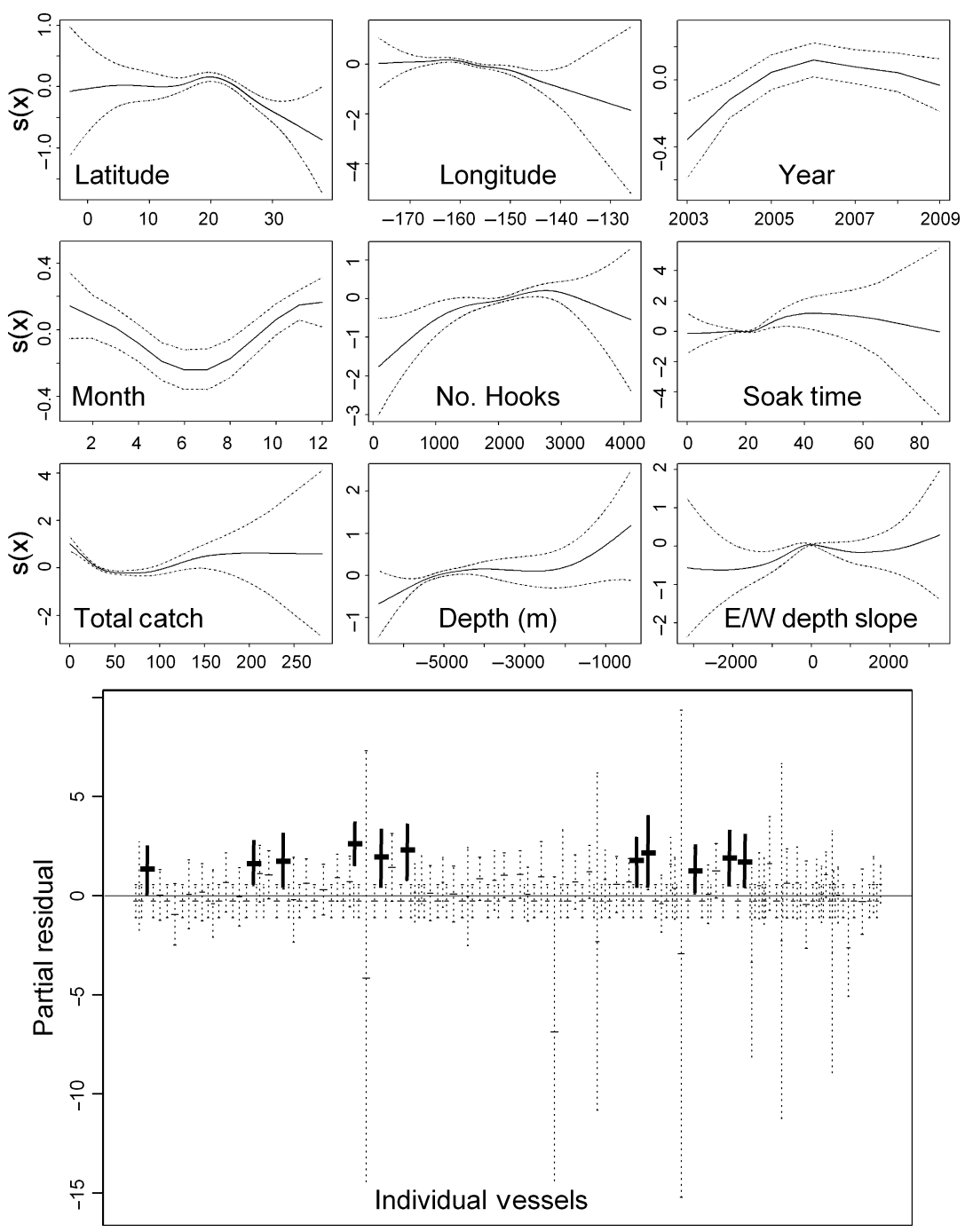

most commonly cut the line when false killer whales or blackfish are hooked, rather than attempting to de-hook animals. An examination of interaction events suggested that up to $58 \%$ of false killer whales or blackfish that were seriously injured were caught in a manner that might have allowed the animal to be freed from gear and released with non-serious injuries if the line had not been cut or broken.

Small reductions in false killer whale bycatch $(6 \%)$ were achieved at current levels of effort (17,200 deep sets and 1600 shallow sets per year) in simulations that included only sets with small circle hooks in the deep-set fishery (Table 5). This was essentially the same result as a shift of 3,000 sets from the deep-set fishery to the shallow-set fishery. More drastic measures involving a complete closure of areas east of $164^{\circ} \mathrm{W}$ within the U.S. exclusive economic zone (EEZ) around Hawaii or restricting all deep-set fishing to east of $150^{\circ} \mathrm{W}$ resulted in
7-15\% reductions in false killer whale bycatch but were considered non-viable economically by the TRT. When combined with an assumed increase in the proportion of animals released with non-serious injuries (from 11 to $50 \%$ because of anticipated efforts by vessel crew to release animals from gear), the small circle hook restriction resulted in an overall $47 \%$ decrease in false killer whale bycatch in the simulations.

\section{Discussion}

Although the GAMs identified several statistically significant correlates of false killer whale depredation and bycatch in the deep-set fishery, the amount of explained variation was extremely low (6.6 and 18\%, respectively) and most of the identified variables were of limited practical value because of economic constraints on the fishery. The decrease in depredation rates (Fig. 4) at higher 
Table 4. Results for the best-fit GAM predicting false killer whale and blackfish bycatch in the deep-set fishery.

\begin{tabular}{lllrl}
\hline Predictor variable & df & Npar df & \multicolumn{1}{l}{$\chi^{2}$} & \multicolumn{1}{l}{$P$} \\
\hline (Intercept) & 1 & & & \\
s(YR) & 1 & 3 & 9.596 & 0.0215 \\
s(NUM.FLTS) & 1 & 2.9 & 6.670 & 0.0768 \\
s(CATCH.ALL) & 1 & 2.8 & 2.332 & 0.4677 \\
s(SST) & 1 & 2.8 & 6.196 & 0.0914 \\
s(SSH) & 1 & 2.9 & 10.072 & 0.0171 \\
Null deviance: 295.26 on 1202 degrees of freedom & \\
Residual deviance: 242.43 on 1183 degrees of freedom & \\
\hline
\end{tabular}

$\mathrm{df}=$ degrees of freedom; Npar $=$ non-parametric. See Table 2 for variable abbreviations.

latitudes and more easterly longitudes corresponded in part to the decreased abundance of false killer whales, a tropical species, in those areas. Apparent seasonal changes in depredation rates were linked to changes in the distribution of effort throughout the year (with fishing taking place at higher latitudes during the second and third quarters). The increase and subsequent leveling off of depredation rates between 2003 and 2009 (Fig. 4) could indicate that false killer whales have learned to target fishing vessels, increasing overall rates through time, but this is speculative and not entirely consistent with the existence of substantial longline fisheries in this area since the early 1990s. It is possible that the observers' ability to identify damage consistently increased during the initial years following implementation of the protocols to record damage type. The increase in depredation on sets that were preceded by a set experiencing depredation does suggest some degree of vessel-following by false killer whales, which are often found in highly spread out groups across many tens of square kilometers. A distance of $100 \mathrm{~km}$ between sets might reduce the repeat depredation risk slightly, by about $16 \%$. Although none of the available vessel-specific factors was identified to explain apparent vessel-specific effects, it is possible that such effects could have been caused by other, unreported factors, such as the acoustic properties of the vessel or the type and quantity of lights used during fishing operations.

Total catch, soak time, and the number of hooks all represent measures of the duration of operations, but functional forms differed among these variables. Depredation rates increased nearly linearly with the number of hooks, while soak time (from set begin to end haul) appeared to have a threshold effect around $24 \mathrm{~h}$ (the typical duration of a set). The relationship with total catch was slightly counterintuitive because lower catch corresponded to high depredation rates; this could be caused in part by fishermen aborting sets when they observe evidence of depredation. Lastly, the significance of depth and slope relationships is unclear, given the wide area and diverse regions in which the fishery operates. One interesting result of the present analysis is that mainline length, which was a significant predictor of marine mammal interaction rates in the Atlantic longline fishery (Garrison 2007), did not correlate with bycatch or depredation rates in the Hawaii-based deep-set fishery. This difference might be attributable to differences in geographic distribution of Pacific and Atlantic fisheries: in the Atlantic, both the longline fishery and the primary
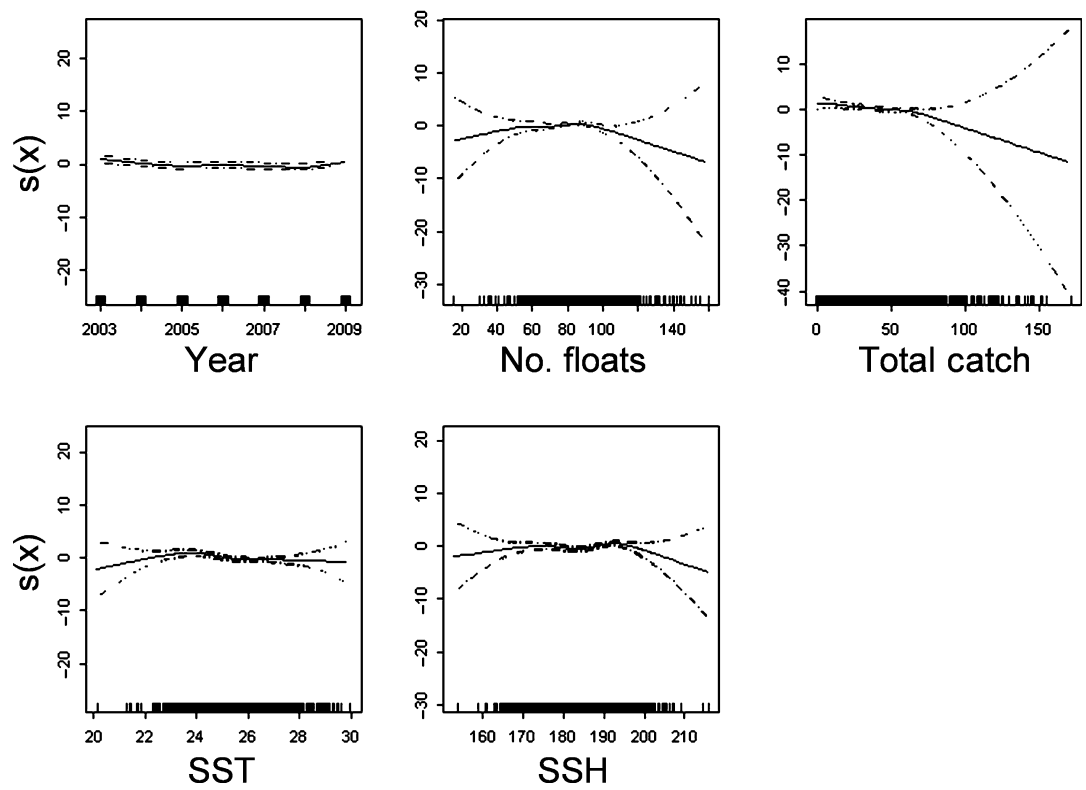

Fig. 5. Functional forms and standard error bands for the predictors of false killer whale bycatch included in the best-fit GAM. $S(x)$ represents the smoothing spline of the indicated predictor variable. 
Table 5. Outcomes for select scenarios evaluated in the simulations.

\begin{tabular}{|c|c|}
\hline Simulation restriction & $\begin{array}{l}\text { Mean change } \\
\text { in false killer } \\
\text { whale mortality } \\
\text { and serious } \\
\text { injury (\%) }\end{array}$ \\
\hline $\begin{array}{l}\text { Prohibit deep-set longline fishing east of } 164^{\circ} \mathrm{W} \\
\text { within the U.S. EEZ around Hawaii }\end{array}$ & -15 \\
\hline Prohibit deep-set longline fishing west of $150^{\circ} \mathrm{W}^{\mathrm{a}}$ & -7 \\
\hline $\begin{array}{l}\text { Require small circle hooks (14/0-16/0) in deep-set } \\
\text { longline fishery }\end{array}$ & -6 \\
\hline $\begin{array}{l}\text { Require small circle hooks and increase the } \\
\text { proportion of animals released with non-serious } \\
\text { injuries to } 50 \%\end{array}$ & -47 \\
\hline $\begin{array}{l}\text { Shift } 3000 \text { sets per year from the deep-set to the } \\
\text { shallow-set longline fishery }\end{array}$ & -6 \\
\hline $\begin{array}{l}\text { Shift } 3000 \text { sets per year from the deep-set to the } \\
\text { shallow-set longline fishery and increase the } \\
\text { proportion of non-serious injuries to } 50 \%\end{array}$ & -48 \\
\hline
\end{tabular}

aThis would close the core area of the fishery, see Fig. 1.

species involved in depredation (pilot whales, Globicephala spp.) are concentrated along the shelf break, whereas in the Pacific, the fishery and false killer whales are spread more sparsely across a larger geographic area. In the Pacific, false killer whales roam at low density over vast areas in search of prey species that are also targeted by the fishery (e.g. tunas, billfish, wahoo, mahimahi).

False killer whale bycatch patterns identified by the GAM followed similar patterns to depredation with respect to variables affecting the duration of operations (number of floats and total catch), but the interannual pattern was weak and did not show an increasing trend as with depredation rates. Combined, this suggests that although depredation rates may have increased between 2003 and 2006, the likelihood of a false killer whale becoming hooked or entangled while engaged in depredation has not changed markedly. Of the 1179 deep sets with depredation, only 22 sets $(1.9 \%)$ resulted in false killer whales or blackfish caught. The strongest relationships were identified with respect to two habitat variables, SST and SSH, although it is unclear how or whether these variables could produce a causal effect on bycatch rates in sets with depredation. The extent to which other species that are known to take catch from longlines (e.g. shortfinned pilot whales) might have been involved in the deep sets with depredation cannot be assessed at present because observers are not able to determine the cetacean species involved in depredation.

The detailed inspection of all false killer whale interactions suggested that small circle hooks might be a potential gear modification to reduce bycatch rates in the deep-set fishery, but hook type was not identified as a significant predictor in the GAM, perhaps because too few animals were caught on small circle hooks. However, the simulation that included only sets using small circle hooks did identify an expected decrease in false killer whale bycatch of about $6 \%$. The detailed evaluation of all 43 false killer whale interactions also indicated that whales are more likely to be captured on hooks in the center of each longline basket, but it was not possible to identify whether this might be caused by gear effects (e.g. more line slack in the center of a basket), animal behavior (e.g. avoidance of hooks closest to floats by false killer whales), or patterns of target species catch (e.g. whether preferred prey items for false killer whales are more frequently caught on the deeper hooks at the center of the basket). Further, little is known about how and when false killer whales depredate and are caught (during setting, soaking, and/or hauling of gear), although anecdotal evidence from fishermen indicates depredation can take place at any time during a set.

Although the GAM of depredation rates (Table 3) identified latitude, longitude, and month as significant predictors, the TRT did not consider large-scale time/area closures to be economically viable as a measure to avoid false killer whales because the seasonal effort shifts are related to the distribution and quality of bigeye tuna (Fig. 1, WPFMC 2010). The simulations evaluated by the TRT revealed that a switch to small circle hooks would be about as effective as the large area closures considered (Table 4). The deep-set fleet has already gradually increased the use of small circle hooks because they are considered more effective at catching bigeye tuna. This is a unique and fortunate instance where a potential gear modification to reduce the bycatch of a protected species might also benefit the fishing industry by increasing catch efficiency. However, the evidence for increased target species catches is largely anecdotal. In the simulations in this study, average bigeye catch rates for sets using small circle hooks were similar to the overall fleet average ( 4.3 versus 4.0 per 1000 hooks, respectively). Experimental verification of bigeye catch rates on small circle hooks is required to resolve the question of impacts on catch efficiency. Further, although large circle hooks (18/0) have been required since 2004 to protect sea turtles in the shallow-set fishery, potential effects of small circle hooks on sea turtles or other protected species in the deep-set fishery are not known at present and should be further evaluated.

The analyses presented here are by no means an exhaustive examination of bycatch and depredation patterns, but instead were intended as a guide for understanding the processes involved and identifying potential mitigation measures for the fisheries. These fisheries are unique among U.S. pelagic fisheries with bycatch and 
depredation problems in that an extensive, systematically collected database existed with which to evaluate potential patterns. During preliminary analyses, alternate analytical approaches to those presented here were considered, including Mantel tests and classification and regression trees, and results were qualitatively similar. The summaries, models, and simulations presented here provide basic information on patterns of depredation and bycatch within the available observer data; these are currently the best indication of expected future circumstances, but changes in fishing behavior or regulations could impact the outcome of any mitigation measures adopted.

The results of this study suggest that, at the present time, there are no viable options for reducing overlap between the Hawaii-based deep-set longline fishery and false killer whales, which target many of the same species. Depredation does not appear linked to any specific times, areas, or vessel, gear, and set characteristics in a way that would allow the development of useful spatial depredation mitigation measures. Acoustic or mechanical deterrents have been investigated elsewhere with limited success (Donoghue et al. 2002; McPherson et al. 2009), but further acoustic studies within the Hawaii-based longline fisheries could increase our understanding of the processes and mechanisms by which false killer whales detect fishing vessels, depredate catch, and get hooked or entangled in longline gear. Based on the data available in this study, it appears likely that small circle hooks could result in a slight decrease in the frequency of false killer whale hookings or entanglements, and a greater chance of releasing animals with non-serious injuries, particularly if fishermen ensure that the hook is the weakest link in the terminal tackle, as recommended by the TRT (see Draft False Killer Whale Take Reduction Plan, submitted to the National Marine Fisheries Service 19 July 2010; available at http:// www.nmfs.noaa.gov/pr/interactions/fkwtrt; accessed 17 December 2010). Additional experiments to evaluate the feasibility of using weaker hooks in this fishery (allowing more false killer whales to pull free of the hook) were also recommended as part of the Draft Take Reduction Plan. These measures represent the first steps towards decreasing bycatch of false killer whales in the deep-set longline fishery and will no doubt be subject to refinement and modification in the future. Efforts are currently underway to characterize false killer whale habitat within the central North Pacific from independent linetransect survey data (E.A. Becker, K.A. Forney, D.G. Foley and J. Barlow, in preparation), and future studies could combine habitat-based density models with fishery interaction data in a spatially and temporally explicit analysis (e.g. using maximum entropy models, Phillips et al. 2006; Friedlaender et al. in press).

\section{Conclusions}

Despite the substantial data available to evaluate patterns of bycatch and depredation in Hawaii-based longline fisheries, 'the catch' in this case is that options are limited when fisheries exploit the same species as marine predators that are susceptible to bycatch, such as false killer whales. In this case, there are no easy solutions for eliminating or substantially reducing depredation, which would be the optimal outcome to reduce economic losses to the fishery and ensure minimal impacts to cetaceans. However, a small, $16 \%$ reduction in repeat depredation appears possible if vessels move about $100 \mathrm{~km}$ following an initial set with depredation. This study has also shown that the use of small (14/0-16/0) circle hooks may reduce levels of bycatch and potentially increase chances of releasing hooked or entangled animals with non-serious injuries. Furthermore, the analyses presented here formed the basis for a Draft False Killer Whale Take Reduction Plan developed through collaborative efforts involving scientists, fishermen, conservation groups, and other stakeholders on the TRT. Sustainable fisheries are critical for maintaining marine biodiversity; if successful, the potential solutions identified here and in future experiments can aid in achieving greater sustainability of longline fisheries worldwide.

\section{Acknowledgements}

We wish to thank the many observers and staff members of the observer program who spent long hours collecting, entering, and verifying the observer data that formed the basis of this analysis, and the fishing industry for their cooperation with observers at sea. The members of the False Killer Whale Take Reduction Team provided valuable input and feedback on several of the analyses presented. Funding for this research was provided by the NMFS Pacific Islands Region, Pacific Islands Fisheries Science Center, and the Southwest Fisheries Science Center. This manuscript was improved by the helpful reviews of S. Benson, J. Carretta, W. Perrin, N. Young and two anonymous reviewers. Special thanks to Lisa Levin for inviting the lead author (K.A.F.) to contribute to this special issue honoring Paul Dayton. Paul has been an incredible friend and mentor, sharing his unique ecological insights, boundless enthusiasm, and dedication to marine conservation with so many students of diverse disciplines. I am grateful to count myself among them - thank you, Paul!

\section{References}

Agardy T. (2000) Effects of fisheries on marine ecosystems: a conservationist's perspective. ICES Journal of Marine Science, 57, 761-765. 
Andersen M.S., Forney K.A., Cole T.V.N., Eagle T., Angliss R., Long K., Barre L., Van Atta L., Borggaard D., Rowles T., Norberg B., Whaley J., Engleby L. (2008) Differentiating serious and non-serious injury of marine mammals: Report of the Serious Injury Technical Workshop, 10-13 September 2007, Seattle, Washington. U.S. Department of Commerce NOAA Technical Memorandum, NMFS-OPR-39, 94 pp.

Carretta J.V., Forney K.A., Lowry M.S., Barlow J., Baker J., Johnson D., Hanson B., Brownell R.L. Jr, Robbins J., Mattila D.K., Ralls K., Muto M.M., Lynch D., Carswell L. (2010) U.S Pacific marine mammal stock assessments: 2009. U.S. Department of Commerce NOAA Technical Memorandum, NMFS-SWFSC-453, 341 pp.

Chelton D.B., Schlax M.G., Samelson R.M., de Szoeke R.A. (2007) Global observations of large ocean eddies. Geophysical Research Letters, 34, L15606.

Chelton D.B., Schlax M.G., Samelson R.M. (2011) Global observations of nonlinear mesoscale eddies. Progress in Oceanography, doi: 10.1016/j.pocean.2011.01.002.

Cheung W.W.L., Lam V.W.Y., Sarmiento J.L., Kearney K., Watson R., Pauly D. (2009) Projecting global marine biodiversity impacts under climate change scenarios. Fish and Fisheries, 10, 235-251.

Derraik J.G.B. (2002) The pollution of the marine environment by plastic debris: a review. Marine Pollution Bulletin, 44, 842-852.

Donoghue M., Reeves R.R., Stone G.S. (2003) Report of the workshop on interactions between cetaceans and longline fisheries, Apia, Samoa: November 2002. New England Aquarium Aquatic Forum Series Report 03-1, Available from: Global Marine Programs Division, New England Aquarium, Central Wharf, Boston, MA. 45p.

Forney K.A. (2010) Serious-injury determinations for cetaceans caught in Hawaii longline fisheries during 1994-2008. U.S. Department of Commerce NOAA Technical Memorandum, NMFS-SWFSC-462, 19 pp.

Forney K.A., Kobayashi D.R. (2007) Updated estimates of mortality and injury of cetaceans in the Hawaii-based longline fishery, 1994-2005. U.S. Department of Commerce NOAA Technical Memorandum, NMFS-SWFSC-412, $30 \mathrm{pp}$.

Friedlaender A.S., Johnston D.W., Fraser W.R., Burns J., Halpin P.N., Costa D.P. (in press) Ecological niche modeling of sympatric krill predators around Marguerite Bay, Western Antarctic Peninsula. Deep Sea Research Part II, doi:10.1016/ j.dsr2.2010.11.018.

Garrison L. (2007) Interactions between marine mammals and pelagic longline fishing gear in the U.S. Atlantic Ocean between 1992 and 2004. Fishery Bulletin, 105, 408-417.

Gilman E., Kobayashi D., Swenarton T., Brothers N., Dalzell P., Kinan-Kelly I. (2007) Reducing sea turtle interactions in the Hawaii-based longline swordfish fishery. Biological Conservation, 139, 19-28.

Gilman E., Kobayashi D., Chaloupka M. (2008) Reducing seabird bycatch in the Hawaii longline tuna fishery. Endangered Species Research, 5, 309-323.

Gray J.S. (1997) Marine biodiversity: patterns, threats and conservation needs. Biodiversity and Conservation, 6, 153-175.

Hall M.A., Alverson D.L., Metuzal K.I. (2000) By-catch: problems and solutions. Marine Pollution Bulletin, 41, 204-219.

Hastie T.J., Tibshirani R.J. (1990) Generalized Additive Models, Vol. 43. Chapman \& Hall/CRC, Boca Raton, FL.

Klein P., Lapeyre G. (2009) The oceanic vertical pump induced by mesoscale and submesoscale turbulence. Annual Review of Marine Science, 1, 351-375.

Lewison R.L., Crowder L.B., Read A.J., Freeman S.A. (2004) Understanding impacts of fisheries bycatch on marine megafauna. Trends in Ecology and Evolution, 19, 598-604.

McPherson G.R., Clague C.I., McPherson C.R., Madry A., Bedwell I., Turner P., Cato D.H., Kreutz D. (2009) Reduction of interactions by toothed whales with fishing gear - Phase 1, development and assessment of depredation mitigation devices around longlines. Fisheries Research and Development Corporation Project Report, Project No. 2003/016, Australia.

Norse E.A. (1995) Maintaining the world's marine biological diversity. Bulletin of Marine Science, 57, 10-13.

Oleson E.M., Boggs C.H., Forney K.A., Hanson M.B., Kobayashi D.R., Taylor B.L., Wade P.R., Ylitalo G.M. (2010) Status review of Hawaiian insular false killer whales (Pseudorca crassidens) under the Endangered Species Act. U.S. Department of Commerce NOAA Technical Memorandum, NMFS-PIFSC-22, 140 pp. + Appendices.

Phillips S.J., Anderson R.P., Schapire R.E. (2006) Maximum entropy modeling of species geographic distributions. Ecological Modelling, 190, 231-259.

Read A.J., Drinker P., Northridge S. (2006) Bycatch of marine mammals in U.S. and global fisheries. Conservation Biology, 20, 163-169.

Smith W.H.F., Sandwell D.T. (1997) Global seafloor topography from satellite altimetry and ship depth soundings. Science, 277, 1957-1962.

TEC Inc. (2009) Cetacean depredation in the Hawaii longline fishery: interviews of longline vessel owners and captains. Report prepared for National Oceanic and Atmospheric Administration National Marine Fisheries Service, Pacific Islands Regional Office, Honolulu.

Wessel P., Smith W.H.F. (1991) Free software helps map and display data. Eos, Transactions, American Geophysical Union, 72, 441.

WPFMC (2010) Pelagic Fisheries of the Western Pacific Region 2008 Annual Report. Western Pacific Fishery Management Council, Honolulu: 282 pp. 